\title{
Medication Usage Evaluation in Patients Prescribed with Ganciclovir in Bone Marrow Transplantation
}

Kashif Ali ${ }^{1, *}$, Fakhsheena Anjum ${ }^{1}$, Mehwish Wajdi $^{2}$, Zubeda Bhutto ${ }^{3}$, Rida Naseem ${ }^{4}$, Tahir Sultan Shamsi ${ }^{4}$

${ }^{1}$ Dow College of Pharmacy, Dow University of Health Sciences Karachi, Pakistan.

${ }^{2}$ Federal Urdu University of arts sciences and technology, Karachi, Pakistan.

3 Institute of Nursing, Dow University of Health Sciences, Karachi, Pakistan.

${ }^{4}$ National Institute of Blood Diseases and Bone Marrow Transplantation, Karachi, Pakistan.

Authors' Contributions

1 Conception \& Study Design, Data Collection

\& Processing.

2 Data Analysis and/or Interpretation, Drafting

of Manuscript.

3 and 4 Data Collection \& Processing.

5 Drafting of Manuscript.

6 Critical Review.

Acknowledgement

Article info.

Received: June 09, 2020

Accepted: December 20, 2020

Funding Source: Nil

Conflict of Interest: Nil

Cite this article: Ali $K$, Anjum F, Wajdi $M$, Bhutto Z, Naseem R, Shamsi TS. Medication Usage Evaluation in Patients Prescribed with

Ganciclovir in Bone Marrow Transplantation.

RADS J Pharm Pharm Sci. 2020; 8(3):129133.

*Address of Correspondence Author: kashif.ali@duhs.edu.pk

\section{A B S T R A C T}

Background: Cytomegalovirus (CMV) is one of the leading risks in bone marrow transplantation for which Ganciclovir is choice of therapy requiring monitoring due to its cytotoxic potential.

Study objectives: The aim of this study was to assess the use of Ganciclovir in the management of CMV in hemato-oncologic patients.

Methods: The study was designed to assess the usage pattern of Ganciclovir in concordance with the predefined assessment criteria. The medical record of patients was extracted by a senior clinical pharmacist from the specialty of hematology-Oncology in a hospital located in Karachi, Pakistan. Patients' records of 2016-2017 (24 months) were collected both retrospectively and prospectively to review with CMV positive infection; the nurses' performance regarding drug storage, handling, and preparation for administration was also observed. Assessment criteria were developed to evaluate the appropriateness of Ganciclovir use by applying standard treatment guidelines adapted from the Lexicomp drug monograph specifying its usage details, USP 800 (United States Pharmacopeia) and NIOSH Guidelines The collected data were categorized and analyzed by using Statistical Package for Social Sciences software, version 16.0.

Results: For this study, 42 cases with CMV positive infection were observed. Out of $n=42$ cases, $n=23(54.76 \%)$ had drug interaction with mycophenolate mofetil and $n=1(2.38 \%)$ case had drug interaction with imipenem cilastatin. Ganciclovir was stopped in $n=8(19.04 \%)$ patients due to development of adverse drug reaction (febrile neutropenia). It was observed by the senior clinical pharmacist that neither the pharmacists nor the nurses were aware of protocol for Ganciclovir handling as per standard treatment guidelines.

Conclusion: Ganciclovir was inappropriately managed by the Nurses and Pharmacists which can be improved by developing and implementing local guidelines according to standard protocol.

Keywords: Cytomegalovirus, Ganciclovir, Bone Marrow Transplant, Transplant. 


\section{INTRODUCTION}

A common complication of immunosuppression is Cytomegalovirus (CMV) infection which can be seen frequently in: (a) patients with the acquired immunodeficiency syndrome (AIDS), (b) in those who received steroids and (c) in transplant recipients. Physicians opt for the reduction of immunosuppression when there are no effective antiviral medications against CMV. CMV therapy has been 'relatively straightforward' even with the introduction of intravenous Ganciclovir (GCV). By following viral loads of patients who did and did not have CMV infection after transplantation, Cope et al. worked out on the viral load at which treatment could be initiated [1]. Cytomegalovirus (CMV) infection is a chief complication after allogeneic stem cell transplantation [2]. All the patients administered with the therapy should be monitored closely for adverse effects as well as for response.

Ganciclovir (GCV) was the first antiviral agent approved for treatment of CMV disease, and remains the first-line treatment for CMV infection and CMV disease in transplant recipients [3]. The side effects of GCV include hematologic abnormalities table:1 (primarily neutropenia, anemia, and thrombocytopenia) and, based on preclinical toxicological studies, probable long-term reproductive toxicity [4].

In a bone marrow transplant study, patients were given study drug from the time of engraftment until 100 days post-transplant. The incidence of CMV disease occurring within the first 100 days posttransplant was significantly less in the GCV arm (1/37 patients, $3 \%)$ as compared to the placebo arm (15/35 patients, 43\%; $p<0.00001)$. In addition, patients receiving GCV had significantly greater overall survival than the placebo group; on both 100 and 180 days post-transplantation ( $p=0.041$ and 0.027 , respectively) [5].

Ganciclovir Guidelines for systemic use (as per Lexicomp and NIOSH 2016) [6,7] are as stated in Table 1.

Table 1. Ganciclovir Guidelines for Systemic Use.

\begin{tabular}{|c|c|}
\hline Dose & $\begin{array}{l}\text { For Bone marrow transplantation (Allogeneic): } 5 \mathrm{mg} / \mathrm{kg} / \mathrm{dose} \text { BID (12hrs) for } \\
5 \text { to } 7 \text { days, then } 5 \mathrm{mg} / \mathrm{kg} / \text { dose every OD (24hrs) until day } 100 \text { post- } \\
\text { transplant }\end{array}$ \\
\hline Infusion & $\begin{array}{l}\text { Rapid infusion can increase toxicity so slow infusion must be considered, } \\
\text { minimum (1hr). Line should be flush with normal saline } 0.9 \% \text { before and } \\
\text { after administration. }\end{array}$ \\
\hline Renal dose & Renal dose adjustment required in case of renal compromised patients \\
\hline Hazardous agent & $\begin{array}{c}\text { NIOSH approved ventilated engineering controls (Vertical hood) (a class II } \\
\text { biological safety cabinet), double gloving; a protective gown is required } \\
\text { during preparation, handling and administration. [12]. }\end{array}$ \\
\hline Drug adverse reaction: & Anemia, neutropenia and thrombocytopenia. \\
\hline \multirow{2}{*}{$\begin{array}{l}\text { Drug Interactions Open } \\
\text { Interactions }\end{array}$} & $\begin{array}{l}\text { Imipenem: Ganciclovir may enhance the adverse/toxic effect of Imipenem. } \\
\text { Specifically, the risk of seizures may be increased. }\end{array}$ \\
\hline & $\begin{array}{l}\text { Mycophenolate: May increase the serum concentration of Ganciclovir. } \\
\text { Probenecid: May increase the serum concentration of Ganciclovir. }\end{array}$ \\
\hline Administration: & $\begin{array}{l}\text { Make sure patients are sufficiently hydrated. Infuse dilution into veins with } \\
\text { sufficient blood flow. }\end{array}$ \\
\hline \multirow[t]{2}{*}{ Monitoring } & $\begin{array}{l}\text { Complete blood count and platelet count two times weekly, serum creatinine } \\
\text { once weekly. [13] }\end{array}$ \\
\hline & Ganciclovir is contraindicated if the hemoglobin level is $<8 \mathrm{~g} / \mathrm{dl}$ \\
\hline
\end{tabular}


MUE (medication use evaluation) programs should be planned in various settings for the drugs that require monitoring or special handling or if prescribed to be used for specific diseases or special populations. Recipients of transplantation get combinations of immune-suppressants which make them more prone to increased danger for cytomegalovirus (CMV) opportunistic infections. Ganciclovir is used for the management and prevention of CMV is in such patients [8,9].

Pharmacists as a part of multidisciplinary healthcare team can play an important role in MUE programs, thereby improving patient outcomes and minimizing total costs [10-14]. The medication use can be much improved through health-care staff education.

To the best of our knowledge, no specific and comprehensive study has been conducted yet to determine the utilization pattern of Ganciclovir in allogeneic bone marrow transplantation. This study was undertaken as a preliminary step for the development of local guidelines for the handling, administration and monitoring of Ganciclovir in allogeneic bone marrow transplantation patients.

\section{METHODS}

This is an institutional approved study which was designed to assess Ganciclovir utilization according to the predefined assessment criteria as per Lexicomp. The medical record of $n=42$ patients was extracted from the 75 bedded specialty of hematology Oncology institute located in Karachi, Pakistan. This institute has several services ranging from blood bank, hematology oncology clinic, daycare unit for blood tranfusions, isolation department and bone marrow transplant unit. Patients' records (2016-2017) with positive CMV infection were prospectively reviewed; patients other than ganciclovir therapy were excluded. Baseline complete blood counts (CBC), hemoglobin $(\mathrm{Hb})$, Total leukocytes count (TLC), Platelets, and Acute neutrophils counts (ANC) of the patients were noted (Table 2). The pharmacists and nurses handling ganciclovir were also observed and their performance for appropriateness was evaluated as per Ganciclovir package insert, USP 800 (United States Pharmacopeia) and NIOSH Guidelines.

\section{Statistical Analysis:}

The collected data were categorized and analyzed using Statistical Package for Social Sciences software, version 16.0.

\section{RESULTS}

A total of $n=42$ cases receiving Ganciclovir (7-19 days; median 12 days) therapy were assessed. There were $\mathrm{n}=31(73.80 \%)$ males and $\mathrm{n}=11$ (26.19\%) females suffering from anemia, b thalassemia major and leukemia (Table 2). Among the cases, baseline hematological findings were noted (Table 2). Out of 42 cases, $n=23(54.76 \%)$ had drug interaction with mycophenolate mofetil and $n=1(2.38 \%)$ case had drug interaction with imipenem cilastatin. Ganciclovir was stopped in $n=$ $8(19.04 \%)$ patients due to adverse drug reaction (febrile neutropenia). None of the pharmacists and nurses were aware of Ganciclovir handling as per $\mathrm{NIOSH}$ Guidelines and the United States Pharmacopoeia 800 chapters. [7].

\section{DISCUSSION}

This study was conducted among allogeneic bone marrow transplanted patients admitted to a specialized hematology and oncology institute. A senior clinical pharmacist observed various processes including CMV confirmation by Polymerase Chain reaction $(\mathrm{PCR})$, prescribing the accurate dose of drug in CMV with or without renal dose adjustment by a physician, order received by pharmacists to check accuracy of dose, renal dose adjustment, drug-drug interactions and reconstitution either in aseptic area or on Biological safety cabinet (horizontal hood or vertical hood). After dispensing the sterile preparation, Ganciclovir handling and administration to patients by nurses were documented. The practice was found unsatisfactory in Ganciclovir handling by the nurses who did not follow the precautions [14].

Ganciclovir has to be infused only into the central veins with good blood flow as per reference [14], but it was recorded that some nurses administered it in the peripheral veins also. Mostly, infusion set is flushed with normal saline prior to drug administration, but it was seen in few cases that infusion set was flushed only when the patient needed to be administered with another parenteral 
drug. These findings are in accordance with a recent study also [15].

It was observed in this study that Ganciclovir was stopped in $n=8$ patients due to development of adverse drug reaction (febrile neutropenia), though the patients were well hydrated. The kidney is a major route of excretion of Ganciclovir. Impaired kidney function has shown to extend half-life of the drug and increase in the concentration also, which ultimately influences the frequency of neutropenia [16].

Establishment of medication utilization evaluation MUE in healthcare organization can improve the efficacy of the drug in patients and minimize the adverse drug effects related to treatment. Use of optimum drug treatment can also help in better patients' results and reduction of healthcare costs [16].

\section{CONCLUSION}

This study concludes that Ganciclovir utilization can be improved by following the standard treatment guidelines. Active participation of multidisciplinary healthcare team in developing and implementing MUE are required to accomplish better patient care.

Table 2. Patients' Profile

\begin{tabular}{|c|c|c|}
\hline Gender & Frequency $\mathbf{n}$ & Percentage \% \\
\hline Male & 31 & 73.80 \\
\hline Female & 11 & 26.19 \\
\hline Disease & Frequency $\mathbf{n}$ & Percentage \% \\
\hline Fanconii's Anemia/Aplastic A & 13 & 30.95 \\
\hline CML/AML & 3 & 7.14 \\
\hline B Thalassemia Major & 26 & 61.90 \\
\hline Baseline Hematological findings & Median & Reference Range \\
\hline $\mathrm{Hb}$ [median (IQR)] & 8.80 & $\begin{array}{c}\text { Male: } 13.8 \text { to } 17.2 \text { grams per deciliter }(\mathrm{g} / \mathrm{dL}) \text { or } \\
138 \text { to } 172 \text { grams per liter }(\mathrm{g} / \mathrm{L}) \text { Female: } 12.1 \text { to } \\
15.1 \mathrm{~g} / \mathrm{dL} \text { or } 121 \text { to } 151 \mathrm{~g} / \mathrm{L} \text {. }\end{array}$ \\
\hline TLC[median (IQR)] & 3.1 & $4.3-10.8 \times 109$ cells per liter. \\
\hline $\begin{array}{l}\text { absolute neutrophil count } \\
\text { ANC[median (IQR)] }\end{array}$ & 2.1 & $\begin{array}{c}\text { [Adult] } \\
1,500-8,000(1.5-8.0) \text { neutrophils/mcL }\end{array}$ \\
\hline Platelets[median (IQR)] & 42 & 150 to $400 \times 10^{9} / \mathrm{L}$ \\
\hline Urea levels & 24.5 & 8-15 mmol/L \\
\hline Creatinine levels & 0.30 & 0.5 to $1.2 \mathrm{mg} / \mathrm{dL}$ \\
\hline Febrile Neutropenia & Frequency $\mathbf{n}$ & Percentage \% \\
\hline Yes & 8 & 19.04 \\
\hline No & 34 & 80.95 \\
\hline
\end{tabular}

\section{REFERENCES}

1. Tan BH. Cytomegalovirus treatment. Current treatment options in infectious diseases. 2014;6(3):256-70.

2. Einsele $H$, Reusser $P$, Bornhäuser $M$, Kalhs $P$, Ehninger $\mathrm{G}$, Hebart $\mathrm{H}$, Chalandon $\mathrm{Y}$, Kröger N,
Hertenstein B, Rohde F, EBMT Working Group on Infectious Disease. Oral valganciclovir leads to higher exposure to ganciclovir than intravenous ganciclovir in patients following allogeneic stem cell transplantation. Blood. 2006 ;107(7):3002-8.

3. Razonable RR, Emery VC. Management of CMV infection and disease in transplant patients. 27-29 
February 2004. Herpes: the journal of the IHMF. 2004; 11(3):77-86.

4. Biron KK. Antiviral drugs for cytomegalovirus diseases. Antiviral research. 2006;71(2-3):154-63.

5. Lexicomp. Ganciclovir. In: UpToDate [Internet]. Alphen aan den Rijn (Netherlands): Wolters Kluwer; 2019[cited 2020 Feb 07]. Available from: https://www.uptodate.com/.

6. Gabay M. USP $<800>$ : handling hazardous drugs. Hospital pharmacy. 2014;49(9):811.

7. Kotton CN. CMV: prevention, diagnosis and therapy. American Journal of Transplantation. 2013;13(s3):24-40.

8. McDevitt LM. Etiology and impact of cytomegalovirus disease on solid organ transplant recipients. American journal of health-system pharmacy. 2006 Oct 1;63(19_Supplement_5):S39.

9. Taylor GR, Boland C, Dooley M, Fowler P, Burridge N, McKenzie D, O'Leary K, Gordon-Croal S, Seaton S. SHPA Standards of Practice for Clinical Pharmacy (Supplement). Journal of Pharmacy Practice and Research. 2011;41(2):1445.

10. Mozaffar M, Shahidi S, Badri S. Ganciclovir use evaluation in kidney transplantation departments. Journal of research in pharmacy practice. 2016 Jul;5(3):212.

11. Brenner TS, Godwin HN, Gouveia WA, Hodgkins BD, Kent SS, Kienle PC, Kornfuhrer HJ, Martin ES, May JR, Meyer GE, O'Brien TE. ASHP guidelines: minimum standard for pharmacies in hospitals. Am J Health Syst Pharm. 2013 Sep 15;70(18):1619-30.

12. Tomonari A, Iseki T, Takahashi S, Ooi J, Yamada T, Takasugi K, Nagamura F, Uchimaru K, Tojo A,
Asano S. Ganciclovir-related neutropenia after preemptive therapy for cytomegalovirus infection: comparison between cord blood and bone marrow transplantation. Annals of hematology. 2004;83(9):573-7.

13. Armstrong EP, Byrns PJ, Foster TS, Morris LS, Fulda TR. Drug utilization review: mechanisms to improve its effectiveness and broaden its scope. The US Pharmacopeia Drug Utilization Review Advisory Panel. J Am Pharm Assoc. 2000;40:53845.

14. National Institute for Occupational Safety and Health (NIOSH). NIOSH List of Antineoplastic and Other Hazardous Drugs in Healthcare Settings; 2014. [Last accessed on 2015 Dec 30]. Available from: http://www.cdc.gov/niosh/docs/2014150/pdfs/2014-150.pdf

15. Tomonari A, Iseki T, Takahashi S, Ooi J, Yamada T, Takasugi K, Nagamura F, Uchimaru K, Tojo A, Asano S. Ganciclovir-related neutropenia after preemptive therapy for cytomegalovirus infection: comparison between cord blood and bone marrow transplantation. Annals of hematology. 2004;83(9):573-7.

16. US Department of Health and Human Services; Centers for Disease Control and Prevention; National Institute for Occupational Safety and Health. NIOSH list of antineoplastic and other hazardous drugs in healthcare settings 2016.http://www.cdc.gov/niosh/topics/antineoplasti c/pdf/hazardous-drugs-list_2016-161.pdf. Updated September 2016.Accessed October 5, 2016.

This is an Open Access article distributed under the terms of the Creative Commons Attribution License (http://creativecommons.org/licenses/by/4.0), which permits unrestricted use, distribution, and reproduction in any medium, provided the original work is properly cited. 